\title{
Low estradiol levels in women of reproductive age having low sleep variation
}

\section{Citation}

Merklinger-Gruchala, Anna, Peter T. Ellison, Susan F. Lipson, Inger Thune, and Grazyna Jansienska. 2008. Low estradiol levels in women of reproductive age having low sleep variation. European Journal of Cancer Prevention 17(5):467-472.

\section{Published Version}

http://dx.doi.org/10.1097/CEJ.0b013e3282f75f67

\section{Permanent link}

http://nrs.harvard.edu/urn-3:HUL.InstRepos:2579652

\section{Terms of Use}

This article was downloaded from Harvard University's DASH repository, and is made available under the terms and conditions applicable to Other Posted Material, as set forth at http:// nrs.harvard.edu/urn-3:HUL.InstRepos:dash.current.terms-of-use\#LAA

\section{Share Your Story}

The Harvard community has made this article openly available.

Please share how this access benefits you. Submit a story.

\section{Accessibility}




\title{
Low estradiol levels in women of reproductive age having low sleep variation
}

\author{
Anna Merklinger-Gruchala ${ }^{a}$, Peter T. Ellison ${ }^{\mathrm{b}}$, Susan F. Lipson ${ }^{\mathrm{b}}$, Inger Thune ${ }^{\text {cd }}$, \\ Grazyna Jasienska ${ }^{\mathrm{a}}$, \\ ${ }^{a}$ Department of Epidemiology and Population Studies, Jagiellonian University, Grzegorzecka 20, 31-531 \\ Krakow, Poland \\ ${ }^{b}$ Department of Anthropology, Harvard University, Cambridge, Massachusetts, USA \\ ${ }^{c}$ Department of Epidemiology, University of Tromso, Tromso, \\ ${ }^{d}$ Norway and Ulleval University Hospital, Oslo, Norway \\ Correspondence to Anna Merklinger-Gruchala, , Department of Epidemiology \\ and Population Studies, Jagiellonian University, Collegium Medicum, \\ Grzegorzecka 20,31-531 Krakow, Poland \\ Tel: +48124241380; e-mail:merklinger@cm-uj.krakow.pl
}

\section{ABSTRACT}

Higher exposure to light at night per se and through decrease in sleep duration and night shift work may suppress serum melatonin levels, which in turn may increase the reproductive hormone levels. High levels of steroid hormones, especially estrogens, may be associated with an increase of the breast cancer risk.

This study investigated whether variation in the sleep duration during one entire menstrual cycle corresponds to variation in estradiol levels in healthy, urban women of reproductive age. Ninthy five regularly menstruating women ages 24-36 collected daily saliva samples for one entire menstrual cycle and recorded the number of hours of sleep per night (sleep duration). Saliva samples were analyzed for concentration of 17- $\beta$ estradiol (E2).

We documented, after adjustments for sleep duration, a positive relationship between the sleep variation (coefficient of variation in sleep duration - sleep CV) and estradiol levels in women of reproductive age. Mean levels of E2 differed significantly in women from the lowest sleep CV quartile in comparison to other quartiles $(p<0.001)$. The low sleep variation group, that is the women who sleep regularly, had mean E2 levels $60 \%$ lower than other groups. These results suggest that sleep variation significantly correlates with E2 levels, while sleep duration does not show a statistically significant relationship. According to the breast cancer development hypothesis, increasing the lifetime exposure to endogenous estrogens could result in higher risk of breast cancer.

\section{INTRODUCTION}

Sleep duration and night shift work are related to many aspects of health, possibly including reproduction and risk of breast cancer in women (Davis et al., 2001; Hansen, 2001; 
Schernhammer et al., 2001). Higher exposure to light at night per se and through decrease in sleep duration and night shift work may suppress serum melatonin levels, which in turn may increase the reproductive hormone levels (Cohen et al., 1978; Okatani, et al., 2000; Schernhammer et al., 2004). Women exposure to steroid hormones, especially estrogens, may be associated with an increase of the breast cancer risk (Cauley at al., 1999; Eliassen et al., 2006; Hankinson et al., 1998; Jasienska and Thune, 2001; Missmer et al., 2004; Yu et al., 2003).

Melatonin, a hormone released mainly by pineal gland, whose synthesis and secretion are stimulated by darkness and inhibited by light (Tamarkin et al., 1985, Malpaux, et al., 2001). The connection between melatonin production and estradiol levels has been well established (Brzezinski, 1987, 1988; Yie, 1995; Okatani et al., 2000; Shernhammer et al., 2004). Seasonal variation in daylight has been shown to relate to ovarian function. When melatonin and ovarian activity were measured in a region with a strong seasonal contrast in luminosity (Kauppila et al., 1987) the daytime 12-h melatonin index and daytime urinary melatonin excretion were significantly higher in dark season than during the light season, and was accompanied by decreased mean serum estradiol concentration at the time of ovulation and during the luteal phase of the cycle, indicating lowered ovarian activity. Seasonal difference in ovarian hormones concentrations was also reported by a study on joggers and runners (Ronkainen et al., 1985). Women had lower levels of estradiol, progesterone and testosterone in the dark season than in the light season. Similarly, estradiol concentrations were significantly lower during autumn and winter months, than during light months $(264.7 \pm$ 44.1 and $661.8 \pm 55.1 \mathrm{nmol} / 1$ respectively) when measured in follicular fluid samples which were obtained from the largest pre-ovulatory follicle of 120 women undergoing in-vitro fertilization (Yie et al., 1995). The melatonin concentration in follicular fluid was also higher during the dark season than during the light season (Ronnberg et al., 1990).

We investigated whether variation in the sleep duration during one entire menstrual cycle corresponds to variation in estradiol (E2) levels in healthy urban women of reproductive age.

\section{MATERIALS AND METHODS}

\section{Study participants}

One hundred and thirty six Polish urban women between 24 and 35 years of age (mean age 29.5 years, std. dev. 3.13) were recruited for the study by advertisements between June 2001 and June 2003. Participants of the study were selected if they met the following criteria: 
regular menstrual cycles and no fertility problems, no gynecological and chronic disorders (i.e. diabetes, hypo/hyperthyroidism), not taking any hormonal medication or using hormonal contraception during the 6 months before recruitment, and not having been pregnant or lactating during the 6 months before recruitment. Mean length of menstrual cycle during which saliva samples were collected was 28.9 days (std. dev. 3.83, range of 22-39).

Out of 136 urban women who collected saliva samples for an entire menstrual cycle, 95 participants were included in the main analysis: sleep duration data were not collected for 32 women, and reliable identification of the day of the mid-cycle E2 drop could not be made for 9 participants. The research protocol was approved by the Jagiellonian University Bioethical Committee.

\section{Sleep and estradiol measurements}

Information on average number of hours of sleep per night (sleep duration) was collected daily by questionnaires for one entire menstrual cycle. During the same menstrual cycle women collected daily morning saliva samples. Saliva samples from 20 days (reverse cycle days -5 to -24 ) of each cycle were analyzed for the concentration of E2 using an I125-based radiomunoassay kit (\#39100, Diagnostic Systems Laboratories, Webster, Texas, USA) with published (Jasienska et al., 2004) modifications to the manufacturer's protocol. Before statistical analyses, cycles were aligned on the basis of identification of the day of the midcycle estradiol drop (day 0), which provides a reasonable estimate of the day of ovulation, according to the published methods (Lipson and Ellison, 1996). The mean E2 values from 18 consecutive days of each cycle aligned on day 0 was used in analysis.

\section{Anthropometric measurements, physical activity, dietary and general questionnaires}

A detailed description of anthropometric measurements and assessment of physical activity was published previously Jasienska et al. (2004, 2006). Average daily energy intake (kcal/day) was assessed by 24-h precoded food diary, in which women recorded the type and the portion size of every food item consumed during 24 hours on seven selected days in the menstrual cycle (days 3-6 and days 21-23) (Furberg et al., 2005). An album showing portions of products and meals was used by each women to estimate consumed amounts. From the 24$\mathrm{h}$ food diary, the total energy content of the daily food rations was calculated using the Dieta 2 (version 1.1.) computer software (Institute of Food and Nutrition, Warsaw, Poland). 
Information on birth weight, education, reproductive history, past use of hormonal medication and tobacco was collected by a general questionnaire (partly administered by an interviewer and partly self-reported).

\section{Statistical analysis}

Variation in sleep duration for each woman individually was calculated as the coefficient of variation in sleep duration (sleep CV). Low sleep CV value means that a similar number of hours of sleep each night was recorded during menstrual cycle, whilst high sleep $\mathrm{CV}$ value represents irregularity in circadian rhythm.

Women were divided into quartiles based on the coefficient of variation (CV). Differences among sleep CV groups in potentially confounding factors such as age, birth weight, height, energy intake, physical activity, body composition variables (body weight, body mass index, percentage of body fat) and mean duration of daylight for sample collection month were tested in separate one-way ANOVA analyses with sleep CV as grouping variable. Potential differences among the study groups in the mean duration of daylight were tested in order to control for the confounding effect on seasonality on estradiol levels. Differences between parous and nulliparous women in sleep CV were tested by Student's t-test (sleep CV were logarithmically transformed to correct the skewness of distributions and used as dependent variable in Student's t-test).

In order to test if quartiles of sleep CV differ in sleep duration we performed ANOVA analysis with group division criterion as one factor and mean sleep duration as dependent variable, followed by contrasts analysis. An $\alpha$ level of 0.0083 (with the Bonferroni correction) was used to indicate statistical significance. The effect of sleep CV on E2 levels was tested by one-way ANOVA analysis with the same group division criterion as one factor and mean E2 levels as dependent variable. Because it was noticed that sleep quality is associated with E2 (Hollander at al., 2001) and sleep duration may have an influence on the breast cancer risk (Vercasalo, et al., 2005, Mc Elroy et al., 2006), possibly via affecting levels of ovarian hormones, we repeated analysis of covariance with mean sleep duration as the covariate. Covariance analysis was followed by contrasts analysis with an $\alpha$ level of 0.0125 (with the Bonferroni correction) used to indicate statistical significance. For other analyses, the null hypothesis was rejected at the 0.05 level. Statistical analyses were performed with Statistica (version 7.1).

\section{RESULTS}




\section{General characteristics of the sample}

General characteristics of all study subjects and the four groups divided by sleep CV are shown in Table 1. The women from groups with low, moderate, high and very high sleep CV did not differ in age, birth weight, education, energy intake, physical activity, smoking, height, body composition (weight, body fat, BMI), reproductive factors (menarcheal age, length of menstrual cycle) and mean duration of daylight. Similarly, there was no statistically significant difference in sleep CV between parous $(n=41)$ and nulliparous $(n=62)$ women $(t-$ test $=-0.863, \mathrm{p}=0.390$ ). However, four groups of women with different sleep CV show significant variation in sleep duration $\left(\mathrm{F}_{3,100}=7.210, \mathrm{p}<0.001\right)$. The group with very high sleep $\mathrm{CV}$ had shorter sleep duration than low and moderate sleep CV groups $\left(\mathrm{F}_{1,100}=17.591\right.$, $\mathrm{p}<0.001 ; \mathrm{F}_{1,100}=13.294, \mathrm{p}<0,001 ;$ respectively), (Fig. 1).

Table 1. Characteristics of all study participants and of four groups differing in sleep CV

\begin{tabular}{|c|c|c|c|c|c|c|c|c|c|c|c|c|}
\hline & \multicolumn{2}{|c|}{ All women } & \multicolumn{2}{|c|}{$\begin{array}{c}\text { Low sleep CV } \\
\substack{\text { group } \\
N=25}\end{array}$} & \multicolumn{2}{|c|}{$\begin{array}{c}\text { Moderate sleep CV } \\
\text { group } \\
N=22\end{array}$} & \multicolumn{2}{|c|}{$\begin{array}{c}\text { High sleep CV } \\
\substack{\text { group } \\
N=25}\end{array}$} & \multicolumn{2}{|c|}{$\begin{array}{c}\text { Very high sleep CV } \\
\substack{\text { group } \\
N=23}\end{array}$} & \multirow[t]{2}{*}{$\begin{array}{l}\text { Signifi } \\
\text { cance } \\
p \text { for } \\
\text { trend }\end{array}$} & \multirow[t]{2}{*}{$\mathbf{F}$} \\
\hline & Mean & Std.Dev. & Mean & Std.Dev. & Mean & Std.Dev. & Mean & Std.Dev. & Mean & Std.Dev. & & \\
\hline Age (years) & 29.48 & 3.131 & 31.04 & 3.180 & 28.95 & 3.373 & 30.17 & 3.036 & 29.48 & 3.016 & 0.113 & $F_{3,99=} 2.045$ \\
\hline Birth weight $(\mathrm{g})$ & 3320.02 & 627.809 & 3246.67 & 534.353 & 3181.68 & 807.492 & 3391.11 & 512.305 & 3323.33 & 755.552 & 0.723 & $F_{3,81}=0.443$ \\
\hline $\begin{array}{l}\text { Education total } \\
\text { (years)* }\end{array}$ & 16.60 & 2.720 & 16.57 & 2.701 & 16.89 & 3.266 & 16.21 & 2.516 & 16.32 & 2.850 & 0.928 & $F_{3,98}=0.150$ \\
\hline Energy intake $(\mathrm{kcal})^{\star}$ & 1937.25 & 508.472 & 1985.77 & 566.829 & 1994.03 & 575.674 & 1809.90 & 403.033 & 2004.09 & 312.444 & 0.317 & $F_{3,97}=1.190$ \\
\hline $\begin{array}{l}\text { Physical activity } \\
\text { (MET-hour/day) }^{\star}\end{array}$ & 30.56 & 8.185 & 28.71 & 5.016 & 31.34 & 8.406 & 31.55 & 9.877 & 30.72 & 8.719 & 0.671 & $F_{3,100}=0.520$ \\
\hline Body height $(\mathrm{cm})^{*}$ & 164.24 & 6.07 & 163.14 & 5.671 & 163.85 & 5.664 & 164.71 & 6.057 & 165.22 & 6.939 & 0.629 & $F_{3,100}=1.000$ \\
\hline Body weight $(\mathrm{kg})^{*}$ & 60.06 & 8.867 & 57.69 & 7.500 & 60.72 & 9.171 & 61.91 & 8.694 & 59.94 & 10.019 & 0.347 & $\mathrm{~F}_{3,99}=1.110$ \\
\hline Body fat (\%) & 25.78 & 6.822 & 24.87 & 6.408 & 25.99 & 7.374 & 26.94 & 6.34 & 25.26 & 7.458 & 0.703 & $F_{3,98}=0.471$ \\
\hline $\begin{array}{l}\text { Body mass index } \\
\left(\mathrm{kg} / \mathrm{m}^{2}\right)^{*}\end{array}$ & 22.18 & 2.885 & 21.71 & 2.938 & 22.61 & 3.239 & 22.78 & 2.67 & 21.93 & 3.110 & 0.428 & $F_{3,100}=0.930$ \\
\hline $\begin{array}{l}\text { Age at menarche } \\
\text { (years) }^{*}\end{array}$ & 13.30 & 1.384 & 13.24 & 1.422 & 13.61 & 1.447 & 13.22 & 1.265 & 13.44 & 1.502 & 0.742 & $F_{3,97}=0.420$ \\
\hline $\begin{array}{l}\text { Length of menstrual } \\
\text { cycle during sample } \\
\text { collection (days)* }\end{array}$ & 28.88 & 3.831 & 27.41 & 3.153 & 29.30 & 3.878 & 28.59 & 4.247 & 29.84 & 3.496 & 0.098 & $F_{2,101}=0.240$ \\
\hline $\begin{array}{l}\text { Mean duration of } \\
\text { daylight }(\% \text { of } 24 \mathrm{~h})\end{array}$ & 0.56 & 0.058 & 0.56 & 0.050 & 0.57 & 0.050 & 0.55 & 0.063 & 0.56 & 0.068 & 0.870 & $F_{3,98}=0.238$ \\
\hline Sleep CV (\%) & 16.00 & 5.460 & 10.09 & 1.358 & 13.78 & 0.775 & 16.81 & 1.333 & 23.44 & 4.588 & $<0.001$ & $\begin{array}{c}F \\
3,100=132.775\end{array}$ \\
\hline $\begin{array}{l}\text { Sleep duration } \\
\text { (h/day) }\end{array}$ & 7.44 & 0.689 & 7.74 & 0.497 & 7.67 & 0.671 & 7.35 & 0.610 & 7.00 & 0.749 & $<0.001$ & $F_{3,100}=7.210$ \\
\hline $\begin{array}{l}\text { Mean E2 } \\
(\text { from }-9 \text { to }+8) \\
(\text { pmol/l/)* }\end{array}$ & 20.10 & 11.318 & 13.93 & 6.626 & 25.11 & 10.617 & 21.92 & 11.639 & 20.03 & 13.111 & $<0.001$ & $F_{3,91}=5.938$ \\
\hline
\end{tabular}




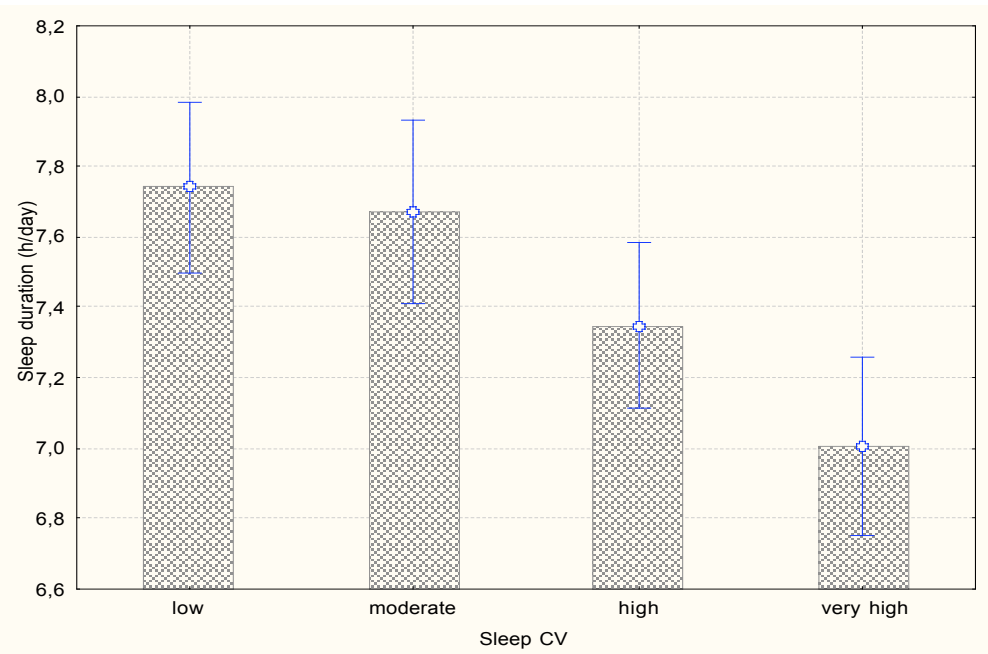

Fig. 1. Mean (with 95\% confidence intervals) sleep duration (h/day) in groups of women with low, moderate, high and very high sleep variation.

\section{Sleep CV and mean sleep duration}

Average coefficient of variation (sleep CV) among study participants was 16.0\% (std. dev. $=5.5 \%$ ) and sleep CV ranged from $7.54 \%$ to $37.45 \%$. The sleep duration varied from 4.76 to 9.28 hours. The average sleep duration was $7.44 \mathrm{~h} /$ day (std. dev. $=0.689$ ) and was comparable to the average duration of sleep noted in representative Polish population sample of 47924 adults over 15 years of age equaled 7.7 h (7.61-7.73 h) (Kiejna et al., 2004). The majority of subjects in our study (63 of 104, or 60.6\%) reported sleep duration between 7-8 h/day. Average sleep duration of less or equal 7 h/day was reported by $24.03 \%$ of women, whereas $15.38 \%$ of women reported sleeping above $8 \mathrm{~h} /$ day.

\section{Estradiol levels and sleep CV}

One-way ANOVA analysis with mean E2 levels as dependent variable, revealed that four groups of women with different sleep variation differ in mean E2 levels $\left(\mathrm{F}_{3,91}=5.938\right.$, $\mathrm{p}<0.001)$. Because sleep duration may also influence the estradiol levels, we conducted the covariance analysis stratified by sleep $\mathrm{CV}$ with mean sleep duration as the covariate. Variation in E2 levels among the four quartiles of sleep CV remained statistically significant $\left(\mathrm{F}_{3,87}=3.102, \mathrm{p}<0.05\right)$. The impact of sleep duration on mean E2 levels was not significant $\left(\mathrm{F}_{1,87}=2.462, \mathrm{p}=0.12\right)$, while the interaction between sleep $\mathrm{CV}$ and sleep duration approach borderline significance $\left(\mathrm{F}_{3,87}=2.582, \mathrm{p}\right.$ for interaction $\left.=0.059\right)$.Contrast analysis indicated that group of women characterized by low sleep variation had significantly lower E2 levels $\left(\mathrm{F}_{1,87}=15.970, \mathrm{p}<0.001\right)$ than all other groups of women (Fig.2). 


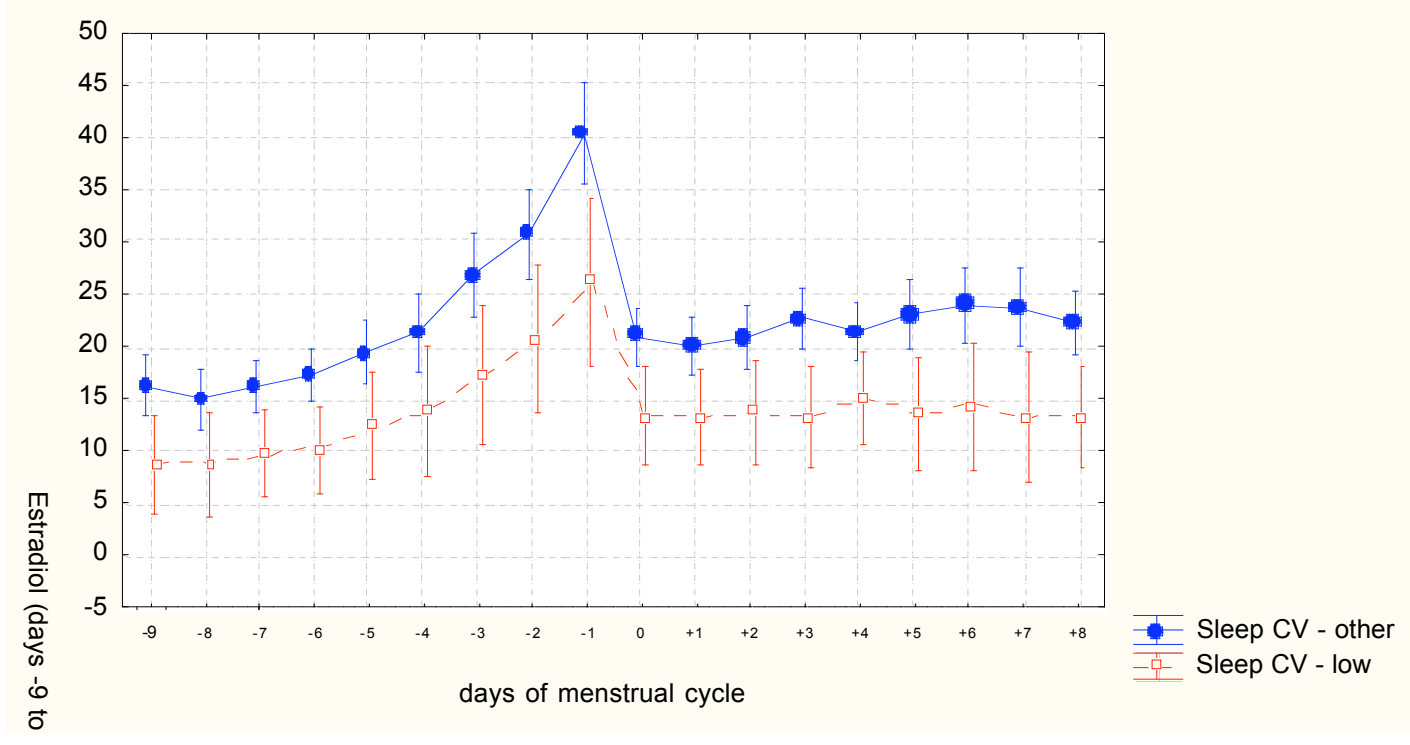

Fig. 2.

Mean (with 95\% confidence intervals) profile of estradiol for group of women with low sleep variation and other (moderate, high and very high) groups combined.

\section{DISCUSSION}

We documented, after adjustments for sleep duration, a positive relationship between the sleep variation and estradiol levels in women of reproductive age. Mean levels of E2 differed significantly in women from the lowest sleep CV quartile in comparison to other quartiles. The low sleep variation group, that is the women who sleep regularly, had mean E2 levels $60 \%$ lower than other groups. We also noticed that the low sleep variation group slept $10.6 \%$ longer than the very high variation group $(7.7 \mathrm{~h} /$ day versus $7.0 \mathrm{~h} /$ day $)$.

These results suggest that sleep duration is not as important as variation in sleep duration. Irregularity in sleep duration is associated with an increase in the E2 levels. According to the breast cancer development hypothesis, increasing the lifetime exposure to endogenous estrogens could result in higher risk of breast cancer.

There is wide-spread agreement for the idea of circadian disruption associated with artificial lighting as the risk factor of the breast cancer incidence in the industrialized world (Stevens, 2006). Observational studies on shift workers having elevated breast cancer risk (Davis et al., 2001; Hansen, 2001; Schernhammer et al., 2001), suggest that not only sleep duration, but also sleep variation may play a role in breast cancer etiology. However, the association between variation in sleep duration and estradiol levels has not been previously documented. One study documented the association of lower E2 levels with poor sleep (Hollander et al., 2001). However poor sleep quality among women aged 45-49 (late 
reproductive age) may not be comparable with sleep irregularity of women ages 24-36 and self-reported questionnaire used to describe insomnia may not correspond to the sleep CV.

Besides ovarian steroids, we did not measure other hormones in this study, so we were not able to test the mechanisms responsible for the link between sleep CV and E2 concentrations. However, melatonin secretion which decrease when people are exposed to light at night (Lewy et al., 1980) may play a role in observed relationship. Switching human volunteers from 8-hour night to 14-hour night results in longer duration of nocturnal melatonin secretion (Wehr, 1991), but it is not known weather melatonin production is dependent on individual sleep variation.

Other mechanisms may also be responsible for the observed relationship between sleep and estradiol concentrations. Short sleep duration was found to be associated with reduction of leptin and elevation of ghrelin (Taheri et al., 2004), that is likely to increase appetite. Leptin, besides its role in body weight (body fat stores) regulation, may be considered an endocrine mediator. Leptin itself exerts effects on different endocrine axes, mainly on the hypothalamic-pituitary-gonadal axis (Wauters et al., 2000). Both in vitro and in vivo experimental evidence indicate that a link between leptin and ovarian steroids exists, but the mechanisms have not been clearly understood. Nonetheless, it was found that in normal weight premenopausal women serum leptin concentrations positively correlated with estradiol and were higher in the luteal than in the follicular phase, with a significant pre-ovulatory peak (Cella et al., 2000; Mannucci et al., 1998).

Moreover, sleep disturbances may lead to other metabolic and hormonal changes, such as impairment in glucose tolerance (Spiegel et al., 1999). Insulin sensitivity is closely linked to the serum levels of sex steroids. Women with impairment in glucose tolerance or type 2 diabetes had significantly higher total and bioavailable estradiol levels than those with normal glucose tolerance (Goodman-Gruen and Barrett-Connor, 2000).

Furthermore, the sleep-debt condition in comparison to the fully rested condition contributes to a disruption (diminishing) of thyrotropin concentrations (Spiegel et al., 1999). It was noticed that TSH was lower in fertile than in infertile patients and low TSH concentrations negatively correlated with E2 in the luteal phase (Gerhard et al., 1991). In addition, thyroid hormones were found in human follicular fluid and thyroid hormone receptors in human granulosa cells (Wakim et al., 1993), suggesting that they might participate in direct regulation of reproductive function in women. It is well known, that thyroid disorders may be connected with menstrual abnormalities (Krassas, 2000) and reproductive failure such as infertility, pregnancy wastage and stillbirths (Joshi et al., 1993). 
The results of our study suggest that lower levels of E2 in women, who sleep regularly, may be one of the mechanisms responsible for the observed relationship between night shift work and breast cancer in women. Therefore, sleep variation may represent one of modifiable risk factors for breast cancer. It may be possible to lower the individual risk of this disease by maintaining more regular circadian rhythm pattern, which may lead to lower lifetime levels of estradiol and thus to reduced risk of breast cancer.

The strength of our study is that estradiol levels were measured in saliva samples collected daily for one entire menstrual cycle by each participant, together with information on number of sleeping hours per night. That methodology allows for the precise and reliable assessment of steroids levels (Jasienska and Jasienski, 2007) and fluctuations in sleep duration.

Because this is the first study that has shown a positive association between sleep variation and estradiol levels in healthy women of reproductive age, after controlling for sleep duration, further studies are needed to confirm these findings. Additional basic science research is also required to identify and determine the mechanisms between sleep irregularity and estradiol levels.

\section{Acknowledgements}

We are grateful to the women who participated in this study, to students of the Faculty of Public Health, Jagiellonian University who worked as research assistants and Dr. Mary O'Rourke from Harvard University. This study was supported by Polish State Committee for Scientific Research (to GJ) and Norwegian Cancer Society.

\section{Bibliography}

1. Bernstein L, Yuan JM, Ross RK, Pike MC, Hanisch R, Lobo R, Stanczyk F, et al. (1990). Serum hormone levels in pre-menopausal Chinese women in Shanghai and white women in Los Angeles: results from two breast cancer case-control studies. Cancer Causes Control 1:51-8.

2. Brzezinski A, Seibel MM, Lynch HJ, Deng M-H, Wurtman RJ (1987). Melatonin in human preovulatory follicular fluid. J Clin Endocrinol Metab 64:865-867.

3. Cauley JA, Lucas FL, Kuller LH, Stone K, Browner W, Cummings SR. Elevated serum estradiol and testosterone concentrations are associated with a high risk for breast cancer (1999). Ann Intern Med 130:270-277. 
4. Cella F, Giordano G, Cordera R. (2000). Serum leptin concentrations during the menstrual cycle in normal-weight women: effects of an oral triphasic estrogen-progestin medication. Eur J Endocrinol 2:1748.

5. Cohen M, Lippman M, Chabner B. (1978). Role of pineal gland in aetiology and treatment of breast cancer. Lancet 8094:814-6.

6. Cos S, Sanchez-Barcelo' EJ (2000). Melatonin - experimental basis for a possible application in breast cancer prevention and treatment. Histol Histopathol 15:637-647.

7. Davis S, Mirick DK., Stevens RG. (2001). Night shift work, light at night, and risk of breast cancer. J Natl Cancer Inst 20:1557-1562.

8. Feychting M, Osterlund B, Ahlbom (1998). A Reduced cancer incidence among the blind. Epidemiology $5: 490-4$

9. Furberg AS, Jasienska G, Bjurstam N, Torjesen PA, Emaus A, Lipson SF, Ellison PT, Thune I. (2005). Metabolic and hormonal profiles: HDL cholesterol as a plausible biomarker of breast cancer risk. the norwegian EBBA study. Cancer Epidemiol Biomarkers Prev 14:33-40.

10. Goodman-Gruen, Barrett-Connor (2000). Sex differences in the association of endogenous sex hormone levels and glucose tolerance status in older men and women. Diabetes Care 7:912-918.

11. Hahn RA. (1991). Profound bilateral blindness and the incidence of breast cancer. Epidemiology 3:20810.

12. Hankinson SE, Willett WC, Manson JE, Colditz GA, Hunter DJ, Spiegelman D, Barbieri RL, Speizer FE. (1998). Plasma sex steroid hormone levels and risk of breast cancer in postmenopausal women. J Natl Cancer Inst 17:1292-9.

13. Hansen J. (2001). Increased breast cancer risk among women who work predominantly at night. Epidemiology 1:74-7.

14. Hansen MA, Garde HA, Hansen J. Diurnal urinary 6-sulfatoxymelatonin levels among healthy Danish nurses during work and leisure time. Chronobiol Int 2006 6:1203-15.

15. Hasler G, Buysse DJ, Klaghofer R, Gamma A, Ajdacic V, Eich D, Rossler, Angst J. (2004). The association between short sleep duration and obesity in young adults: a 13-year prospective study. Sleep 4:661-6

16. Henderson BE, Ross RK, Bernstein L. (1988) Estrogens as a cause of human cancer: The Richard and Hinda Rosenthal Foundation Award Lecture. Cancer Res 48:246.

17. Hollander LE., Freeman EW., Sammel MD., Berlin JA., Grisso JA, Battistini M (2001). Sleep quality, estradiol levels, and behavioral factors in late reproductive age women. Obstet Gynecol 98:391-397.

18. Jasienska G, Ellison PT. (2004). Energetic factors and seasonal changes in ovarian function in women from rural Poland. Am J Hum Biol 16: 1-18.

19. Jasienska G., Jasienski M. (2007). Interpopulation, interindividual, intercycle, and intracycle natural variation in progesterone levels: a quantitative assessment and implications for population studies. American Journal of Human Biology (in press).

20. Jasienska G, Thune I. (2001). Lifestyle, hormones, and risk of breast cancer. Br Med J 322:586-7.

21. Jasienska G, Ziomkiewicz A, Thune I, Lipson S, Ellison PT. (2006). Habitual physical activity and estradiol levels in women of reproductive age. Eur J Cancer Prev 15:439-445. 
22. Joshi JV, Bhandarkar SD, Chadha M, Balaiah D, Shah R. (1993). Menstrual irregularities and lactation failure may precede thyroid dysfunction or goitre. J Postgrad Med 39:137-41.

23. Kauppila A, Kivela A, Pakarinen A, Vakkuri O. (1987). Inverse seasonal relationship between melatonin and ovarian activity in humans in a region with a strong seasonal contrast in luminosity. J Clin Endocrinol Metab 5:823-8.

24. Kiejna A, Rymaszewska J, Wojtyniak B, Stokwiszewski J. (2004). Characteristics of sleep disturbances in Poland - results of the National Health Interview Survey. Acta Neuropsychiatrica 16:124-129.

25. Kliukiene J, Tynes T, Andersen A. (2001). Risk of breast cancer among Norwegian women with visual impairment. Br J Cancer. 3:397-9.

26. Krassas GE. (2000). Thyroid disease and female reproduction. Fertil Steril 6:1063-70.

27. Leon-Blanco MM, Guerrero JM, Reiter RJ, Calvo JR, Pozo D. (2003). Melatonin inhibits telomerase activity in the MCF-7 tumor cell line both in vivo and in vitro. J Pineal Res 3:204.

28. Leproult R, Copinschi G, Buxton O, Van Cauter E. (1997). Sleep loss results in an elevation of cortisol levels the next evening. Sleep 10:865-70.

29. Lewy AJ, Wehr TA, Goodwin FK, Newsome DA, and Markey SP. (1980). Light suppresses melatonin secretion in humans. Science 4475:1267-1269.

30. Malpaux B, Migaud M, Tricoire H, and Chemineau P (2001). Biology of mammalian photoperiodism and the critical role of the pineal gland and melatonin. J Biol Rhythms 16: 336-347.

31. Mannucci E, Ognibene A, Becorpi A, Cremasco F, Pellegrini S, Ottanelli S, Rizzello SM, et al. (1998). Relationship between leptin and oestrogens in healthy women. Eur J Endocrinol 2:198-201.

32. Mayo JC, Sainza RM, Antolína I, Herreraa F, Martin V, Rodrigueza C. (2002). Melatonin regulation of antioxidant enzyme gene expression. Cell Mol Life Sci 59:1706-1713.

33. Missmer SA., Eliassen A.H, Barbieri RL, Hankinson SE. (2004). Endogenous estrogen, androgen, and progesterone concentrations and breast cancer risk among postmenopausal women. J Natl Cancer Inst 24:1856-1865.

34. Pawlikowski M, Kolomecka M, Wojtczak A, Karasek M. (2002). Effects of six months melatonin treatment on sleep quality and serum concentrations of estradiol, cortisol, dehydroepiandrosterone sulfate, and somatomedin C in elderly women. Neuro Endocrinol Lett 23 Suppl 1:17-9.

35. Pinheiro SP, Schernhammer ES, Tworoger SS, Michels KB. (2006). A prospective study on habitual duration of sleep and incidence of breast cancer in a large cohort of women. Cancer Res 66: 5521-5525.

36. Ram PT, Kiefer T, Silverman M, Song Y, Brown GM, Hill SM. (1998). Estrogen receptor transactivation in MCF-7 breast cancer cells by melatonin and growth factors. Mol Cell Endocrinol 141(1-2):53-64.

37. Rodriguez AB, Marchena JM, Nogales G, Duran J, Barriga C. (1999). Correlation between the circadian rhythm of melatonin, phagocytosis, and superoxide anion levels in ring dove heterophils. J Pineal Res 1:35-42.

38. Ronkainen H, Pakarinen A, Kirkinen P, Kauppila A. (1985). Physical exercise-induced changes and season-associated differences in the pituitary-ovarian function of runners and joggers. J Clin Endocrinol Metab 3:416-22. 
39. Ronnberg L, Kauppila A, Leppaluoto J, Martikainen H, Vakkuri O. (1990). Circadian and seasonal variation in human preovulatory follicular fluid melatonin concentration. J Clin Endocrinol Metab 2:4926.

40. Schernhammer ES, Laden F, Speizer FE, Willett WC, Hunter DJ, Kawachi I, Colditz GA. (2001). Rotating night shifts and risk of breast cancer in women participating in the nurses' health study. J Natl Cancer Inst. 20:1563-8.

41. Schernhammer RB, Willett WC. Laden F, Colditz GA, Hankinson SE. (2004). Epidemiology of urinary melatonin in women and its relation to other hormones and night work. Cancer Epidemiol Biomarkers Prev 13: 936-943.

42. Davis S, Mirick DK, Stevens RG (2001). Night shift work, light at night, and risk of breast cancer. J Natl Cancer Inst 20:1557-1562.

43. Shimizu H, Ross RK, Bernstein L, Pike MC, Henderson BE (1990). Serum oestrogen levels in postmenopausal women: comparison of American whites and Japanese in Japan. Br J Cancer 3:451-3.

44. Singh M, Drake CL, Roehrs T, Hudgel DW, Singh TR et al. (2005). The association between obesity and short sleep duration: A population- Based study. J Clin Sleep Med 4:357 - 363.

45. Stevens RG (2006). Artificial lighting in the industrialized word: circadian disruption and breast cancer. Cancer Causes Control 17:501-507.

46. Taheri S, Lin L, Austin D, Young T, Mignot E. (2004). Short sleep duration is associated with reduced leptin, elevated ghrelin, and increased body mass index. PLoS Med 3: 210-217.

47. Tamarkin L, Baird CJ, Almeida OF (1985). Melatonin: a coordinating signal for mammalian reproduction? Science 227: 714-720.

48. Tamarkin L, Danforth D, Lichter A, DeMoss E, Cohen M, Chabner B, and Lippman M. (1982). Decreased nocturnal plasma melatonin peak in patients with estrogen receptor positive breast cancer. Science 4549:1003-1005.

49. Verkasalo PK, Lillberg K, Stevens RG., Hublin C, Partinen M, Koskenvuo M, Kaprio J. (2005). Sleep duration and breast cancer: a prospective cohort study. Cancer Res 65:9595-9600.

50. Wakim AN, Polizotto SL, Buffo MJ, Marrero MA, Burholt DR. (1993). Thyroid hormones in human follicular fluid and thyroid hormone receptors in human granulosa cells. Fertil Steril 6:1187-90.

51. Wauters M, Considine R, Van Gaal L. (2000). Human leptin: from an adipocyte hormone to an endocrine mediator. Eur J Endocrinol 143:293-311.

52. Woo MM, Chen-Jei T, Keun Kang S, Nathwani PS, Fun Pang S, Leung P. (2001). Direct Action of melatonin in human granulosa-luteal cells. J Clin Endocrinol Metab 10:4789-4797.

53. Yie SM, Brown GM, Liu GY, Collins JA, Daya S, Hughes EG, Foster WG, Younglai EV. (1995a). Melatonin and steroids in human pre-ovulatory follicular fluid: seasonal variations and granulosa cell steroid production. Hum Reprod 1:50-55.

54. Yie SM, Niles LP, Younglai EV. (1995b). Melatonin receptors on human granulosa cell membranes. J Clin Endocrinol Metab 80:1747-1749.

55. Yu H, Shu XO, Shi R, Dai Q, Jin F, Gao YT, Li BDL, Zheng W. (2003). Plasma sex steroid hormones and breast cancer risk in Chinese women. Int J Cancer 105:92-97. 
56. Wehr TA. (1991). The durations of human melatonin secretion and sleep respond to changes in daylength (photoperiod). J Clin Endocrinol Metab 6:1276-80. 